\title{
FLIGHT OF THE SALT MARSH TABANIDAE (DIPTERA), TABANUS NIGROVITTATUS, CHRYSOPS ATLANTICUS AND C. FULIGINOSUS: CORRELATION WITH TEMPERATURE, LIGHT, MOISTURE AND WIND VELOCITY ${ }^{1}$
}

\author{
By W. E. Dale and R. C. Axtell ${ }^{2}$
}

\begin{abstract}
The flight activities of the greenhead fly, Tabanus nigrovittatus Macquart (collected by traps), and deer flies, Chrysops atlanticus Pechuman and Chrysops fuliginosus Wiedemann (both collected by netting from a human), were measured in the field and correlated with the environmental conditions during the collection periods. The highest number of $T$. nigrovittatus were correlated with intermediate light intensity $(40,000$ lux), temperatures around $25^{\circ} \mathrm{C}$ and no wind. C. atlanticus was most active at relatively low light intensity (5000 lux), high temperatures $\left(30^{\circ} \mathrm{C}\right)$ and air moisture equivalent to $8 \mathrm{~mm} \mathrm{Hg}$ vapor pressure deficit. The greatest activity of $C$. fuliginosus was correlated with high levels of light (100,000 lux). Graphs are presented for both actual and predicted levels of flight activity for the significantly correlated values of light, VPD, temperature and wind for each species.
\end{abstract}

Evidence presented by Park (1940), CloudsleyThompson (1961) and others indicates that even if there is a more or less fixed rhythmic periodicity in insects, the duration of the periodic activity may be shortened, delayed or eliminated by the effects of environmental factors such as light, temperature, air moisture and wind. Flight activity of adult tabanids seems to coincide with certain levels of light intensity; most of the species are considered to be diurnal (Hine 1906, Pechuman 1957, 1972), but according to Pechuman (1957), Tabanus sackeni Fairchild is crepuscular and Chrysops shermani Hine is nocturnal. The flight activity of several upland species of Tabanus has been studied by use of $\mathrm{CO}_{2}^{-}$ baited malaise traps. Roberts (1974) showed qualitatively that flight activity is influenced by light intensity and, in a quantitative analysis, Burnett \& Hays (1974) concluded that barometric pressure was of greatest influence, with other factors (such as temperature, evaporation, sky radiation, wind, and relative humidity) showing lesser degrees of correlation.

From general observations, there appear to be relationships between environmental conditions and

\footnotetext{
${ }^{1}$ This research was supported in part by an Agency for International Development, U. S. Department of State fellowship, and by NOAA Office of Sea Grant Department of Commerce, under Grant No. 04-3-158-40. Paper No. 4540 of the Journal Series of the North Carolina Agricultural Experiment Station.

${ }^{2}$ Predoctoral Fellow and Professor, respectively, Department of Entomology, North Carolina State University, Raleigh, N. C. 27607, U.S.A. Present address of W.E.D.: Department of Entomology, Universidad Nacional Agraria, LaMolina, Lima, Peru.
}

the activity of Tabanus nigrovittatus Macquart, Chrysops atlanticus Pechuman and C. fuliginosus Wiedemann which are common species in coastal salt marshes of eastern North America. The only published quantitative study on salt marsh species is by Joyce \& Hansens (1968), who correlated temperature, cloudiness and wind velocity with the relative abundance of $T$. nigrovittatus and $T$. lineola Fabricius collected on sticky panels. Catts \& Olkowski (1972) correlated mating behavior and flight of $C$. fuliginosus with air temperature.

The present field study was designed to measure quantitatively the correlations (from 1/2-hr records) of temperature, vapor pressure deficit, wind velocity and light with the relative activity of $T$. nigrovittatus, C. atlanticus and C. fuliginosus in and adjacent to a North Carolina salt marsh.

\section{MATERIALS AND METHODS}

\section{Collection methods}

These studies were conducted in an area described by Dukes et al. (1974) adjacent to Newport River, Morehead City, Carteret Co., North Carolina, during 1973. Eastern standard time was used.

$T$. nigrovittatus was collected by 2 box traps positioned $30 \mathrm{~m}$ apart in the upper middle section of a tidal salt marsh dominated by smooth cordgrass, Spartina alterniflora Loiseleur. The traps (Dale \& Axtell 1975) were basically the type used in New Jersey (Hansens et al. 1971) with a screen collecter mounted on top of a black box which was ca $80 \mathrm{~cm}^{2}$, $40 \mathrm{~cm}$ high and stood on 4 legs ca $1 \mathrm{~m}$ above the ground. The collections were made on 10 consecutive days (1-10 June) during the species peak abundance. The trapped flies were removed each $1 / 2 \mathrm{hr}$ from 0500 to $2030 \mathrm{hr}$. To ensure more rapid movements of the flies from the body of the trap upwards towards the light and into the collecting container, most of the trap was darkened inside by covering with a thick cloth for $2 \mathrm{~min}$. prior to removal of the collection. The flies inside the collecting containers were anesthetized with $\mathrm{CO}_{2}$, identified and liberated in the same area. The number of flies from both traps was averaged for each collection period. 
C. atlanticus was studied in the periphery of a woodland dominated by Pinus taeda Linnaeus. The collections were made on 10 consecutive days (19-28 May) during the seasonal peak of abundance of this species. One adult male human was used as bait. Every $1 / 2 \mathrm{hr}$ from 0500 to $2000 \mathrm{hr}$ he walked twice along a path $100 \mathrm{~m}$ long. The flies were captured with a net (35 cm diam.) moved in a "figure-eight" pattern above the upper back, neck and head of the collector. A uniform speed (ca $4 \mathrm{~km} / \mathrm{hr}$ ), 200 net strokes per collection and similar dress colors were maintained throughout the study. At the end of the collection, the flies were anesthetized with $\mathrm{CO}_{2}$, identified and liberated in the same area.

C. fuliginosus was collected in the transition zone between a $S$. alterniflora tidal salt marsh and a $P$. taeda woodland. The study was made for 8 consecutive days (6-13 May) during the peak of abundance for the species. The collections were taken every $1 / 2 \mathrm{hr}$ from 0530 to $1900 \mathrm{hr}$ using the same method described for $C$. atlanticus.

\section{Environmental data}

The sensitive parts of all the instruments were held $1 \mathrm{~m}$ above the ground in the center of the collection sites. Air temperatures $\left({ }^{\circ} \mathrm{C}\right)$ were measured with a shaded mercury thermometer. Relative air moisture was determined by taking dry and wet thermometer temperatures with an electrical suction psychrometer (Bendix-Psychron ${ }^{\circledR}$ model $\left.556-2\right)^{3}$ and later transformed to vapor pressure deficits (VPD) in $\mathrm{mm}$ of mercury. Wind velocity $(\mathrm{m} / \mathrm{min}$.) was measured with a No. 03AM680 Slow Speed Anemometer $^{4}$ (range 6 to $300 \mathrm{~m} / \mathrm{min}$.) by exposing the movable parts of the instrument perpendicular to the wind direction. Light was measured with a portable photometer (Berry \& Raney 1968). A model CL 505L Clairex ${ }^{\circledR}$ photoconductive cell ${ }^{5}$ permitted readings from less than 1 lux up to 110,000 lux. Each light measurement was the mean of 2 readings, one with the cell directed towards the sun, the other with the cell pointing towards the sky and perpendicular to the ground.

For $T$. nigrovittatus, each environmental datum was the mean of 3 readings taken at the beginning, middle and end of the 1/2-hr collection period. For $C$. atlanticus and $C$. fuliginosus, the mean of readings taken at the beginning and end of each collection was used.

\footnotetext{
${ }^{3}$ Bendix, Environmental Science Division, Baltimore, Md. 21204, U.S.A.

${ }^{4}$ G. M. Mfg. and Instrument Corporation, New York, N. Y. 10451, U.S.A.

${ }^{5}$ Clairex Electronics, Mt. Vernon, N. Y. 10551, U.S.A.
}

\section{Analysis of the data}

The numbers of flies were transformed to $\sqrt{\mathrm{X}}+1$ to stabilize their variance. These values were regressed with the following parameters: date, hour, temperature (TEMP), temperature $\times$ temperature (STEMP), wind, wind $\times$ wind (SWIND), vapor pressure deficit (VPD), vapor pressure deficit $\times$ vapor pressure deficit (SVPD), reciprocal of the vapor pressure deficit (RVPD), light, and square root of light (ROOTLI). Parameters were retained in a multiple regression model when their values showed a partial F-statistic significant at 0.10 level. These calculations were made by the Backward Elimination Procedure described by Service (1972) using the Research Triangle IBM 360/165 computer.

The actual numbers of flies collected (for each species) were graphed along with the corresponding significantly correlated environmental factor (FIG. $1,4,7)$. The curve for means was obtained by uniting consecutive partial means of each of the collection periods; the curves for maximums and minimums were constructed with the highest and

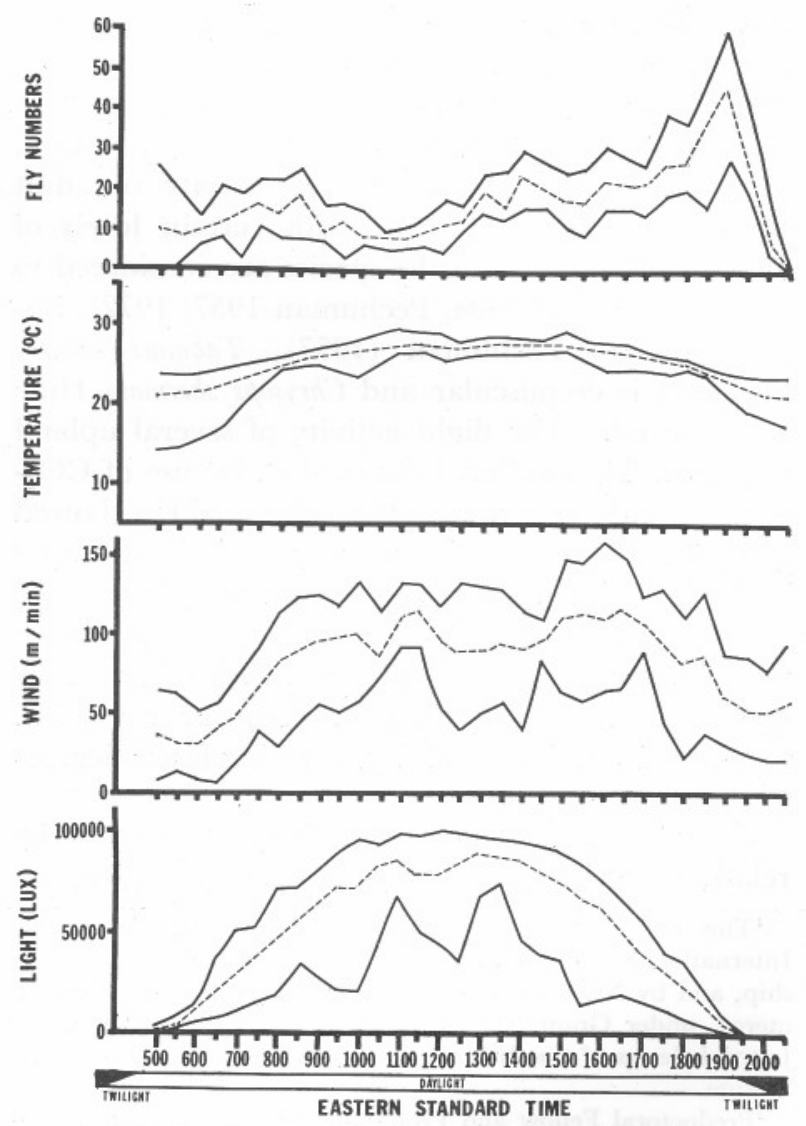

FIG. 1. Maximum, minimum and means (---) for numbers of Tabanus nigrovittatus; temperature, wind velocities and light at different collection periods of the day. 
lowest values observed in each of the collection periods. The lower scale in the figures shows the mean dark, nautical twilight and light periods for the time and location of the study, as obtained from the Nautical Almanac (U.S. Naval Observatory and Her Majesty's Stationery Office 1971).

In addition, predictive curves which illustrate the correlation between the expected number of flies and the specific environmental parameters were obtained by uniting consecutive predictive values of numbers of flies at selected levels of the parameters under study, and by the use of the predictive regression equation; all the remaining parameters were maintained in the equation at their mean values over the entire experiment. The predictive equation for each species was obtained with a simple regression model analysis (Service 1972).

\section{RESULTS AND DISCUSSION}

\section{Tabanus nigrovittatus}

FIG. 1 presents, for each of the collection periods, the maximum, minimum and mean numbers of flies trapped from 0500 to $2030 \mathrm{hr}$, along with the maximums, minimums and means of temperature, wind velocity and light intensity. TABLE 1 shows the relative contribution of the significant parameters on the analysis of the activity of this species. These parameters accounted for ca $38 \%$ of the activity variability $\left(R^{2}=0.3799\right)$. The remaining sources of variability were not identified. Increasing temperatures, an intermediate level of light and low wind velocity were significant parameters which were correlated with higher numbers of active flies. Air moisture, ranging from 0.94 to $17.54 \mathrm{~mm} \mathrm{Hg}$, was not correlated with flight activity. This analysis required the assumptions that variation in the environmental conditions did not affect the

TABLE 1. Significant parameters (see text, p. 552) and results of statistical analysis for Tabanus nigrovittatus.

\begin{tabular}{|c|c|c|c|}
\hline Parameter & $\begin{array}{c}\text { DeGREES } \\
\text { OF } \\
\text { FREEDOM }\end{array}$ & $\begin{array}{l}\text { REGRESSION } \\
\text { COEFFICIENT }\end{array}$ & F statistic \\
\hline HOUR & 1 & 0.01279206 & $23.016 * * * * *$ \\
\hline ROOTLI & 1 & 0.01929269 & $22.685 * * * * *$ \\
\hline LIGHT & 1 & -0.00004906 & $20.922 * * * * *$ \\
\hline TEMP & 1 & 1.22614937 & $11.265 * * * *$ \\
\hline STEMP & 1 & -0.02456831 & $9.199 * *$ \\
\hline DATE & 1 & -0.06975965 & $3.835 *$ \\
\hline WIND & 1 & -0.00649551 & $3.272^{*}$ \\
\hline ERROR & 156 & & \\
\hline
\end{tabular}

Coefficient of Variation (C.V.) $=26.69 \%$.

Multiple Correlation Coefficients $\left(\mathrm{R}^{2}\right)=0.37990$.

$* * * * * \mathrm{P}<0.0001, * * * * \mathrm{P}<0.001, * * \mathrm{P}<0.05, * \mathrm{P}<0.1$.

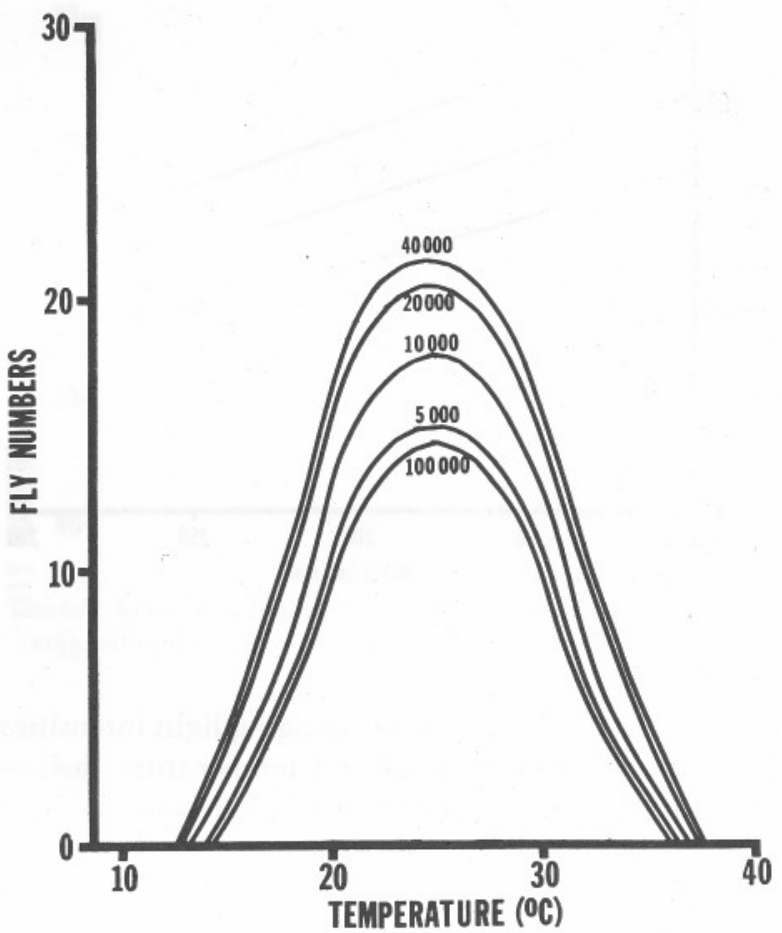

FIG. 2. Predicted relationship of flight activity of Tabanus nigrovittatus to temperature and selected light intensities (lux).

efficiency of the traps and that the fly population level was constant.

FIG. 2 and 3 illustrate the predicted influences of light, temperature, and wind velocity on the flight activity of $T$. nigrovittatus. When a parameter is not noted in 1 graph, the value of that factor was the mean of the whole experiment (hour $=1263.4$ E.S.T.; square root of light $=196.5$ lux $^{1 / 2}$; light $=$ 49143.3 lux; temperature $=26^{\circ} \mathrm{C}$; temperature $\times$ temperature $=638.8^{\circ} \mathrm{C}$; date $=156.8$ day number; wind velocity $=82.2 \mathrm{~m} / \mathrm{min}$.).

Light. This was one of the factors most highly correlated with the flight activity of $T$. nigrovittatus. FIG. 1 shows that the highest observed mean numbers of flies were trapped at intermediate levels of light. There was a slight peak in early morning (ca 0830 $\mathrm{hr}$ ), lowest numbers in midday (ca $1100 \mathrm{hr}$ ) and increasing numbers in late afternoon with the peak during the twilight period (ca $1900 \mathrm{hr}$ ). The highest predicted numbers of flies coincided with light intensity of ca 40,000 lux over fairly wide ranges of temperature (FIG. 2) and wind velocity (FIG. 3). This high light level corresponds to that at 0730 and $1700 \mathrm{hr}$ during the first $1 / 2$ of May 1973 for North Carolina latitude.

Temperature. Flight activity was highly correlated with this factor. The greatest predicted activity 


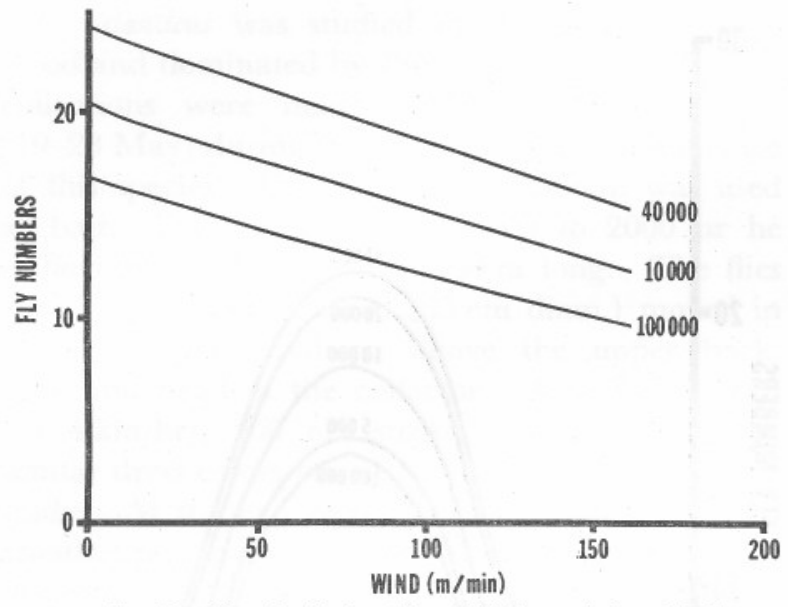

FIG. 3. Predicted relationship of flight activity of Tabanus nigrovittatus to wind velocity at selected light intensities (lux).

occurred at $25^{\circ} \mathrm{C}$ even with changing light intensities (FIG. 2). The lower predicted temperature threshold ranged from $12^{\circ}$ to $14^{\circ} \mathrm{C}$ for light intensities from 5000 to 100,000 lux; with the same light range the upper predicted temperature threshold was between $36^{\circ}$ and $38^{\circ} \mathrm{C}$.

In Massachusetts, Bailey (1947) observed that "warm days" were favorable for the activity of $T$. nigrovittatus and "cold days" produced less activity. Joyce \& Hansens (1968) similarly found a high correlation between mean and maximum daily temperature with fly activity; their partial correlation coefficients were positive, which is indicative of directly proportional variation in both variables.

Wind velocity. FIG. 3 presents the relationship between flight activity and wind velocities at selected light intensities. Maximum flight activity was predicted to occur without wind, and increasing wind velocities were correlated with proportional decline in flight activity. Within a light range from 0 to 100,000 lux, the wind velocity threshold was predicted to be between 550 and $670 \mathrm{~m} / \mathrm{min}$.

Joyce \& Hansens (1968) found no correlation between the mean activity of the species and the mean wind speed. The discrepancy in our results probably was due to the different approach used. Their study correlated 26 records of daily mean wind velocity with the corresponding daily mean number of flies collected by sticky traps during "afternoon counts." They rejected "morning counts" because "the weather was more uniform" during the afternoon. The mean wind velocity ranged from 92 to $339 \mathrm{~m} / \mathrm{min}$. In our study, over 180 collections were made every $1 / 2 \mathrm{hr}$ during the morning and afternoon by 2 box traps. The mean wind velocity ranged from 7 to $158 \mathrm{~m} / \mathrm{min}$.
FIG. 1 shows that after the onset of flight activity in the morning, the observed mean numbers of flies fluctuated at relatively low levels until $1230 \mathrm{hr}$, while light, temperature, and wind velocity increased. A small peak in fly numbers was observed from 0730 to $0830 \mathrm{hr}$. The flight activity increased from 1300 to $1900 \mathrm{hr}$; in the same period there was a strong decline in mean light intensity and a small reduction in mean temperature. The highest mean flight activity was recorded at $1900 \mathrm{hr}$. Fly activity decreased abruptly from 1900 to $2030 \mathrm{hr}$, during which period high mean temperatures and low mean wind velocities were recorded.

Since the activity of this species was correlated with an intermediate level of light intensity, it may be expected to have 2 "peaks" of activity during the day. However, there may be differences in the intensity of activity due to the effect of other environmental factors which are correlated with activity. The environmental conditions of the morning were different from those in the afternoon. The slow recovery in the morning from low overnight tem-

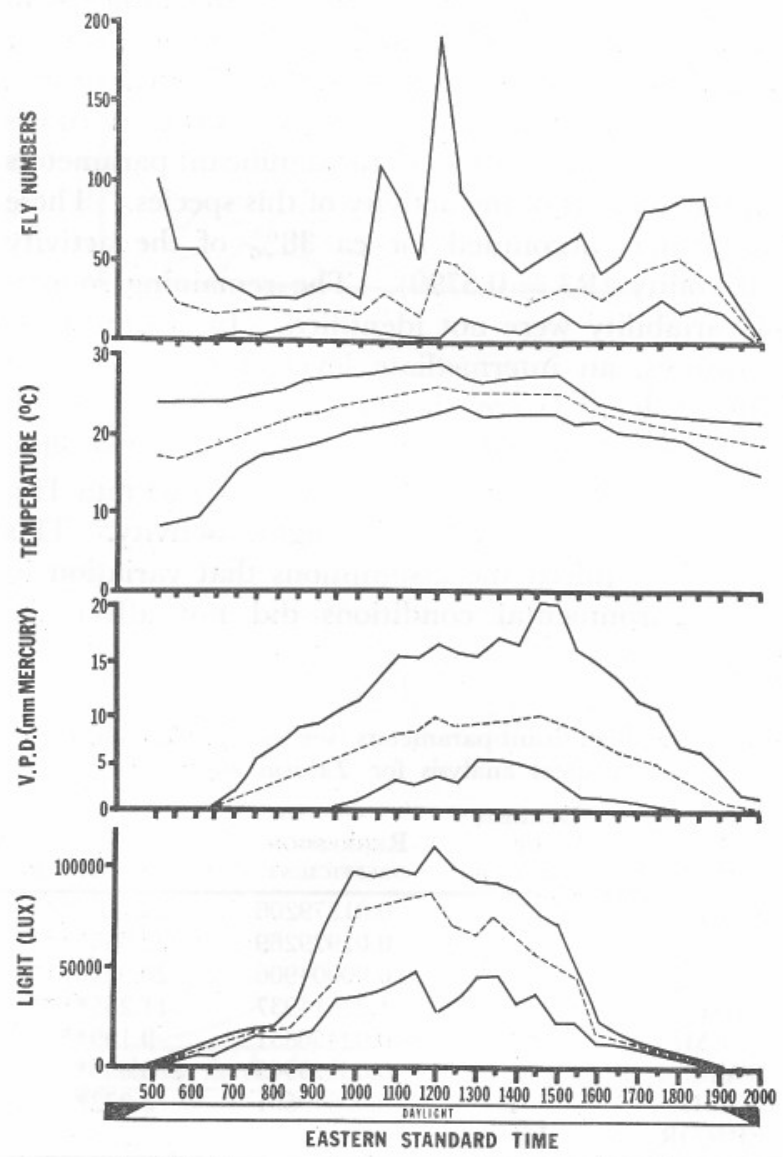

FIG. 4. Maximum, minimum and means (---) for numbers of Chrysops atlanticus; temperature, vapor pressure deficits and light at different collection periods in the day. 
peratures could be responsible for the differences in intensity between these 2 "peaks." On the other hand, the $2 \mathrm{hr}$ lag of time between the optimum predicted light intensity at $1700 \mathrm{hr}$ and the maximum observed activity at $1900 \mathrm{hr}$ could be caused partially by the negative effect of higher wind speed prevailing at $1700 \mathrm{hr}$.

\section{Chrysops atlanticus}

FIG. 4 presents the maximum, minimum and mean numbers of flies collected by overhead netting from 0500 to $2000 \mathrm{hr}$, with the corresponding maximums, minimums and means of temperature, air moisture (VPD) and light intensity.

TABLE 2 gives the relative contribution of the significant environmental parameters on the analysis of the flight activity of this species; using those parameters ca $30 \%$ of the activity variability $\left(\mathrm{R}^{2}=\right.$ 0.30012) was explained. The sources of the remaining variability were not identified.

Assuming that the environmental conditions did not influence the attractiveness of the human host to the flies and that the population in the area sampled was maintained at a constant level during the collection periods, our analysis indicated that high numbers of active flies were correlated with increasing values of temperature and air moisture (relatively low VPD values) and decreasing light intensity. Wind velocities ranging from 0 to $172 \mathrm{~m} / \mathrm{min}$. were not correlated with flight activity.

FIG. 5 and 6 present the relationships of temperature, air moisture and light to the flight activity; when a parameter is not noted in 1 graph, the value of that factor was the mean of the entire experiment (temperature $=22.3^{\circ} \mathrm{C} ; \quad$ light $=35328.6 \quad$ lux; $\mathrm{VPD} \times \mathrm{VPD}=53.4 \mathrm{~mm} \mathrm{Hg} ; \mathrm{VPD}=5.2 \mathrm{~mm}$ $\mathrm{Hg})$.

Temperature. Flight activity of $C$. atlanticus was highly correlated with this factor. The highest activity was predicted to occur at $30^{\circ} \mathrm{C}$ for light ranging from 5000 to 80,000 lux (FIG. 5). Maximum numbers of active flies were predicted at high

TABLE 2. Significant parameters (see text, p. 552) and results of statistical analysis for Chrysops atlanticus.

\begin{tabular}{|c|c|c|c|}
\hline PARAMETER & $\begin{array}{c}\text { DEGREES } \\
\text { OF } \\
\text { FREEDOM }\end{array}$ & $\begin{array}{l}\text { REGRESSION } \\
\text { COEFFICIENT }\end{array}$ & F statistic \\
\hline TEMP & 1 & 0.37133770 & $58.477 * * * * *$ \\
\hline LIGHT & 1 & -0.00003043 & $18.812 * * * * *$ \\
\hline SVPD & 1 & -0.01685996 & $8.931 * * *$ \\
\hline VPD & 1 & 0.26050494 & $7.047 * * *$ \\
\hline ERROR & 155 & & \\
\hline
\end{tabular}

Coefficient of Variation (C.V.) $=41.38 \%$.

Multiple Correlation Coefficient $\left(\mathrm{R}^{2}\right)=0.30012$.

$* * * * * \mathrm{P}<0.0001, * * * \mathrm{P}<0.01$

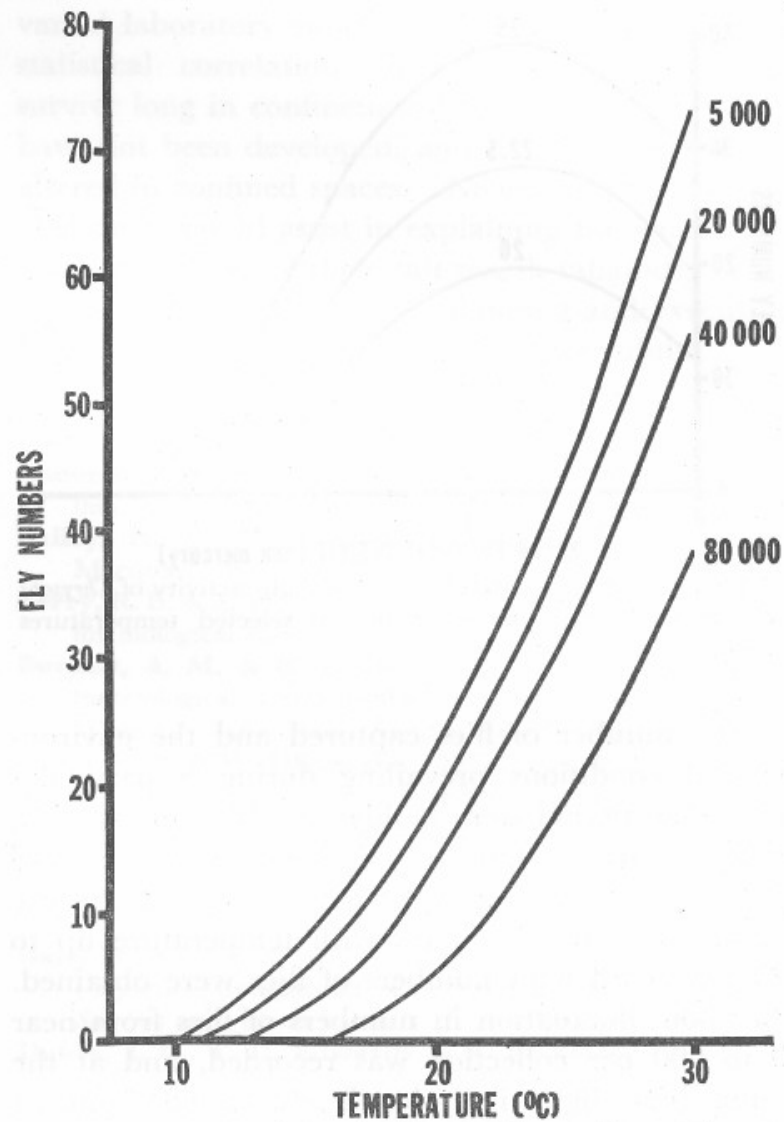

FIG. 5. Predicted relationship of flight activity of Chrysops atlanticus to temperature at selected light intensities (lux).

temperatures with low light intensity. The lower predicted temperature threshold varied from $9.7^{\circ}$ to $15.5^{\circ} \mathrm{C}$; the lowest values were obtained at reduced light intensities. The data did not include an upper temperature threshold, but it is predicted to occur above $30^{\circ} \mathrm{C}$, which is rather high for the time and latitude where the study was done.

Light. This was the 2nd most significant factor correlated with the flight activity of this species. The highest predicted number of active flies was at 5000 lux and at increasing light intensities the number of active flies decreases (FIG. 6). This agrees with our observations of increased activity late in the day and during overcast periods at other times of the day.

Vapor pressure deficit. FIG. 6 illustrates the correlation of this factor with the predicted activity of the flies at different temperatures. The highest predicted number of flies was found at VPD $=8 \mathrm{~mm}$ $\mathrm{Hg}$. Low activity was predicted with VPD values near zero (almost at the saturation point) and for high VPD values (by extrapolation, there would be no expected activity under dry conditions). 


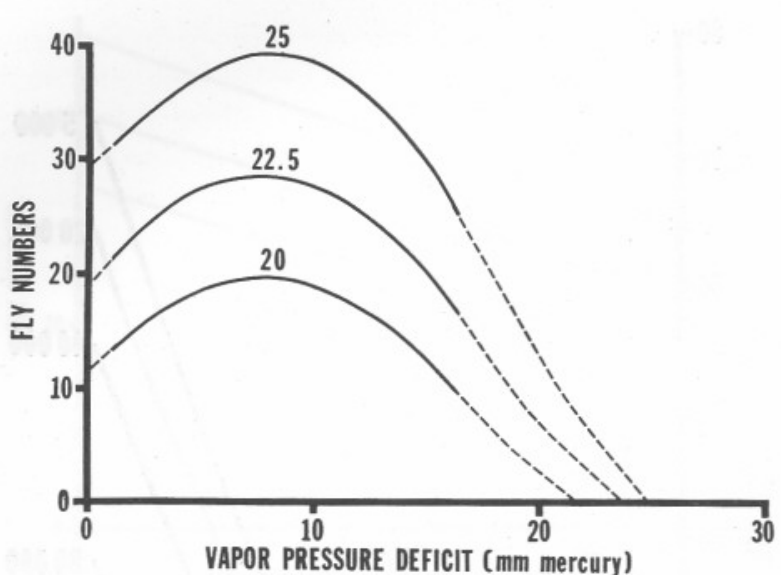

FIG. 6. Predicted relationship of flight activity of Chrysops atlanticus to vapor pressure deficit at selected temperatures $\left({ }^{\circ} \mathrm{C}\right)$.

The number of flies captured and the environmental conditions prevailing during a particular collection period were highly variable (FIG. 4). In those early mornings, with temperature around $10^{\circ} \mathrm{C}$, no flies were collected. However, at the same hour on other days with temperature up to $25^{\circ} \mathrm{C}$, record high numbers of flies were obtained. At noon, fluctuation in numbers of flies from near 0 to 200 per collection was recorded, and at the same time light intensity levels varied from ca 30,000 to above 100,000 lux with greater numbers of flies collected at the lower light levels during overcast periods. Under these conditions, it is not possible to describe the mean flight activity in terms of the time of day. In Connecticut, Anderson (1973), perhaps working under less variable environmental conditions, described the activity of $C$. atlanticus as biphasic, with 1 peak of activity during early morning and another peak in the afternoon. Since our data showed that low levels of light intensity were highly correlated with high numbers of flies, this might account for Anderson's observations of the early morning and afternoon peaks of activity of $C$. atlanticus.

\section{Chrysops fuliginosus}

FIG. 7 presents the maximum, minimum and mean numbers of flies collected by overhead netting from 0530 to $1900 \mathrm{hr}$, with the corresponding maximum, minimum and mean of light intensity.

TABLE 3 shows the relative contribution of light intensity, the only significant environmental factor, and hour on the activity of the species; these parameters explained ca $55 \%$ of the activity variability $\left(\mathrm{R}^{2}=0.5503\right)$. The sources of the remaining variability were not identified. This analysis demonstrated that high numbers of active flies were

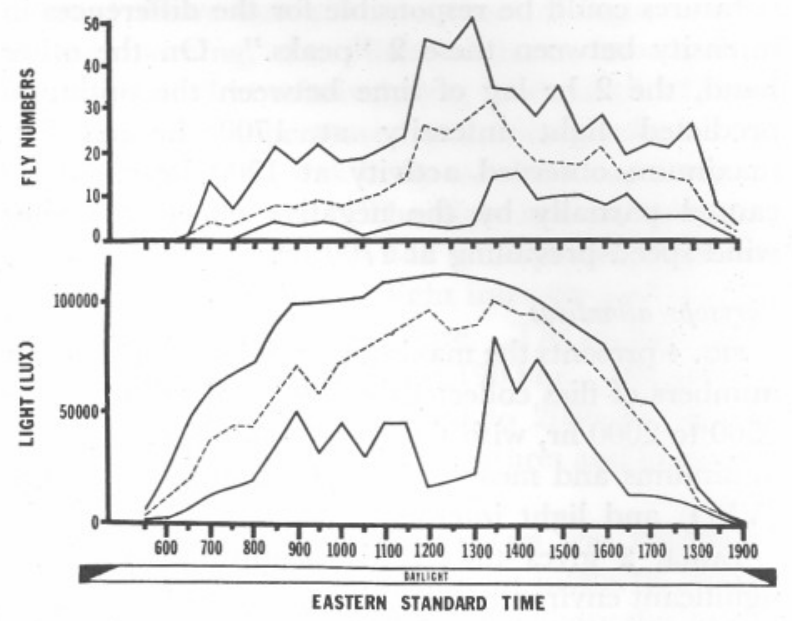

FIG. 7. Maximum, minimum and means (---) for numbers of Chrysops fuliginosus and light at different collection periods in the day.

correlated with increasing light intensity. Temperatures ranging from $4^{\circ}$ to $30^{\circ} \mathrm{C}$, VPD from 0.919 to $22.380 \mathrm{~mm} \mathrm{Hg}$ and wind velocity from 0 to $68.5 \mathrm{~m} / \mathrm{min}$. were not correlated significantly with the activity of the species. The analysis includes the same assumptions as stated for $C$. atlanticus.

FIG. 8 presents the predicted relationship of flight activity with light, with hour represented by its mean over the whole experiment $(121.5 \mathrm{hr})$. Higher activity was predicted to occur at increasing light intensities, with a maximum at 100,000 lux. The lower light threshold for activity was predicted at 26 lux; the data did not include a predicted upper light threshold, but it was calculated to occur well above the 100,000 lux, a level which is unrealistically high under field conditions.

The observed mean activity increased from early morning to $1330 \mathrm{hr}$, when the peak was reached (FIG. 7). Mean activity decreased thereafter and no flies were collected after $1900 \mathrm{hr}$. The maximum observed activity coincided with maximum levels of light intensity.

In Connecticut, Anderson (1973) also observed that $C$. fuliginosus was monophasic. He reported

TABLE 3. Significant parameters (see text, p. 552) and results of statistical analysis for Chrysops fuliginosus.

\begin{tabular}{lccr} 
PARAMETER & $\begin{array}{c}\text { Degrees } \\
\text { OF } \\
\text { FREEDOM }\end{array}$ & $\begin{array}{c}\text { REgRession } \\
\text { COEFFICIENT }\end{array}$ & \multicolumn{1}{c}{ F STATISTIC } \\
\hline ROOTLI & 1 & 0.01043724 & $123.671 * * * * *$ \\
HOUR & 1 & 0.01615312 & $51.667 * * * * *$ \\
ERROR & 140 & & \\
\hline
\end{tabular}

Coefficient of Variation (C.V.) $=32.33 \%$.

Multiple Correlation Coefficient $\left(\mathrm{R}^{2}\right)=0.55029$.

$* * * * * \mathrm{P}<0.0001$. 


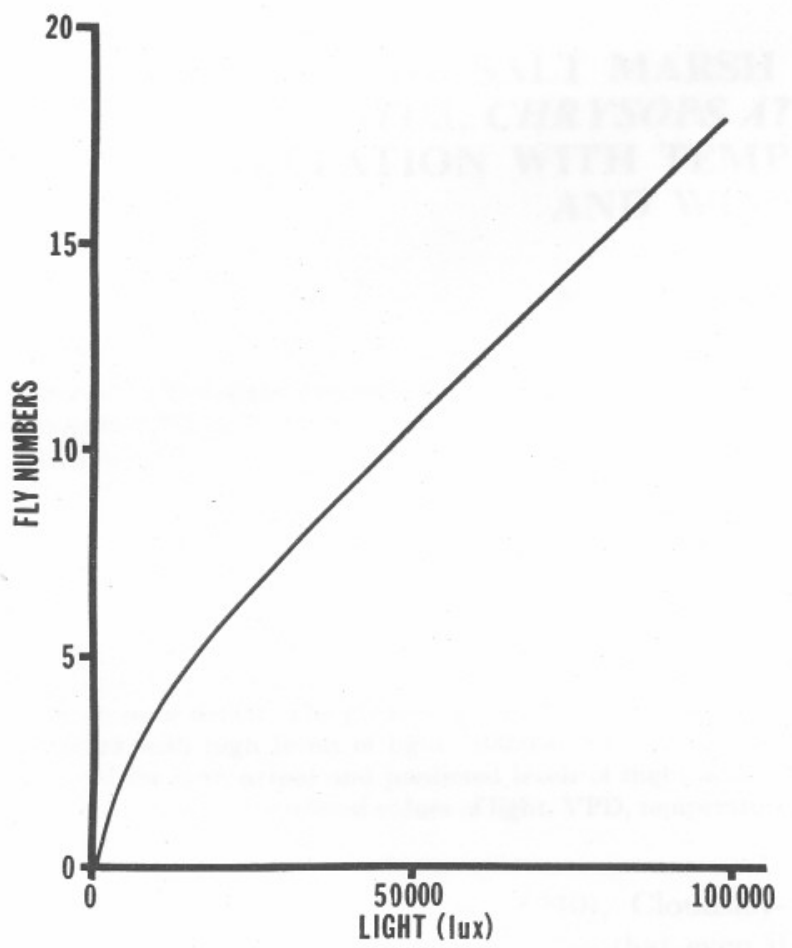

FIG. 8. Predicted relationship of flight activity of Chrysops fuliginosus to light intensity.

the first flies were active at $0645 \mathrm{hr}$; they reached their peak of activity at $1045 \mathrm{hr}$ and were very active until $1300 \mathrm{hr}$; thereafter the numbers declined gradually and very low levels were found after $1615 \mathrm{hr}$.

Our data show that the degree of correlation of the environmental factors with the flight activity was different according to the species of flies. Highest numbers of active $T$. nigrovittatus were collected with intermediate light intensity $(40,000$ lux), temperature around $25^{\circ} \mathrm{C}$ and no wind. The highest activity of $C$. atlanticus coincided with low light intensity (5000 lux), high temperature $\left(30^{\circ} \mathrm{C}\right)$ and air moisture equivalent to $\mathrm{VPD}=8 \mathrm{~mm} \mathrm{Hg}$. Highest numbers of $C$. fuliginosus were correlated with high levels of light (100,000 lux).

Under field conditions and with parameters included in this study, it was only possible to explain part of the variability found in the activity of these species. In order to get a better predictive equation, it would be necessary to measure additional factors, such as physiological state of the species and atmospheric pressure. Experiments under precisely varied laboratory conditions are needed to confirm statistical correlation, but these species do not survive long in confinement, methods for colonizing have not been developed, and fly behavior may be altered in confined spaces. Nevertheless, the available data should assist in explaining the within-day activity patterns of these salt marsh tabanids. This is particularly important in planning and executing chemical control measures against the adults.

\section{LITERATURE CITED}

Anderson, J. F. 1973. Biting behavior of saltmarsh deer flies (Diptera: Tabanidae). Ann. Ent. Soc. Amer. 66: 21-23.

Bailey, N. S. 1947. Field notes on Tabanus nigrovittatus Macquart. Psyche 54: 62-64.

Berry, R. E. \& L. W. Raney. 1968. A recording photometer for biological studies. Ecology 49: 161-62.

Burnett, A. M. \& K. L. Hays. 1974. Some influences of meterological factors on flight activity of female horse flies (Diptera: Tabanidae). Environ. Ent. 3: 515-21.

Catts, E. P. \& W. Olkowski. 1972. Biology of Tabanidae (Diptera): Mating and feeding behavior of Chrysops fuliginosus. Environ. Ent. 1: 448-53.

Cloudsley-Thompson, J. L. 1961. Rhythmic activity in animal physiology and behavior. Academic Press, New York \& London. $235 \mathrm{p}$.

Dale, W. E. \& R. C. Axtell. 1975. Salt marsh Tabanidae (Diptera): Comparison of abundance and distribution in Spartina and Juncus habitats. J. Med. Ent. 12: 671-78.

Dukes, J. C., T. D. Edwards \& R. C. Axtell. 1974. Associations of Tabanidae (Diptera) larvae with plant species in salt marshes, Carteret County, North Carolina. Environ. Ent. 3: 280-86.

Hansens, E. J., E. M. Bosler \& J. W. Robinson. 1971. Use of traps for study and control of saltmarsh greenhead flies. J. Econ. Ent. 64: 1481-86.

Hine, J. H. 1906. Habits and life histories of some flies of the family Tabanidae. Bull. Bur. Ent. U.S. Dept. Agr. 12(pt. II): $19-38$.

Joyce, J. M., Jr \& E. J. Hansens. 1968. The influence of weather on the activity and behavior of greenhead flies Tabanus nigrovittatus and Tabanus lineola. J. N.Y. Ent. Soc. 76: $72-80$.

Park, O. 1940. Nocturnalism-The development of a problem. Ecol. Monogr. 10: 485-536.

Pechuman, L. L. 1957. The Tabanidae of New York. A distributional study. Proc. Rochester Acad. Sci. 10: 121-79.

1972. The horseflies and deerflies of New York (Diptera, Tabanidae). Search, Agr. Vol. 2, No. 5. 72 p.

Roberts, R. H. 1974. Diurnal activity of Tabanidae based on collections in malaise traps. Mosquito News 34: 220-23.

Service, J. 1972. A user's guide to the statistical analysis system. Student Supply Stores, North Carolina State University at Raleigh, Raleigh, N. C. 260 p.

U. S. Naval Observatory and Her Majesty's Stationery Office. 1971. The Nautical Almanac for the year 1973. U. S. Printing Office, Washington, D. C. $276+\mathrm{xxxv}$. 